\title{
FORMAÇÃO DE PROFESSORES NO BRASIL E NA AMÉRICA LATINA NA PERSPECTIVA DA EDUCAÇÃO INCLUSIVA $^{1}$
}

Formación de profesores en Brasily América Latina desde la perspectiva de la educación inclusiva

Teacher training in Brazil and Latin America from the inclusive education perspective

Maria de Fátima Barbosa Abdalla*

Patrícia Cristina Albieri de Almeida**

https://doi.org/10.38117/2675-181X.formov2020.v2i2n4.575-596

\begin{abstract}
RESUMO
Trata-se de uma pesquisa, que tem como objetivo identificar oportunidades formativas para a educação inclusiva no Brasil e em países da América Latina. Parte-se da Teoria das Representações Sociais, de Moscovici, e da Teoria de Ação, de Bourdieu, e de outros referenciais teóricos que discutem as políticas de formação e as de inclusão social, privilegiando a educação para a diversidade. Quanto à metodologia, realizam-se: análise documental; entrevistas com coordenadores dos cursos de Pedagogias; e grupos focais com estudantes. A análise de conteúdo privilegiou duas dimensões analíticas - dimensão pedagógica da inclusão e dimensão de responsabilidade profissional. Por fim, desvenda-se a necessidade da formação inicial em uma perspectiva de educação inclusiva, a fim de que se possibilite um espaço social de convivência mais equânime na direção de garantir os direitos de todos a uma educação justa, igualitária e inclusiva.
\end{abstract}

PALAVRAS CHAVE: Formação de Professores; Brasil; América Latina; Pedagogias de Inclusão; Educação para a Diversidade.

\footnotetext{
${ }^{1}$ Este artigo é uma versão, com outro foco teórico, do texto "Políticas de formação de professores na América Latina: um estudo sobre as pedagogias de inclusão", encaminhado, em 2019, para ser publicado no livro "Políticas Educacionais: questões, diálogos e reflexões", da Universidade Federal do Rio Grande/RS. Alguns dos resultados de pesquisa, aqui revelados, foram apresentados, também, na Mesa Redonda "Pesquisas na Formação de Professores: desafios e perspectivas", no XII Seminário Nacional de Formação de Profissionais da Educação, XI Encontro Nacional FORUMDIR e I Seminário Nacional Forparfor e Forpibid-rp", que ocorreu de 16 a 19 de setembro, em Salvador-Bahia
} 


\title{
RESUMEN
}

Se trata de un estudio cuyo objetivo es el de identificar oportunidades formativas para la educación inclusiva en Brasil y en países de Latinoamérica. Se parte de la Teoría de las Representaciones Sociales, de Moscovici, y de la Teoría de Acción, de Bourdieu, así como de otros referentes teóricos que discuten las políticas de formación y de inclusión social, privilegiando la educación para la diversidad. En lo que se refiere a la metodología se realizaron análisis documental, entrevistas con coordinadores de los cursos de Pedagogías, y grupos focales con estudiantes. En el análisis de contenido se privilegiaron dos dimensiones analíticas - dimensión pedagógica de la inclusión y dimensión de responsabilidad profesional. Por fin, se desvela la necesidad de formación inicial desde una perspectiva de una educación inclusiva, a fin de hacer posible un espacio social de convivencia más ecuánime con el propósito de asegurar los derechos de todos a una educación justa, igualitaria e inclusiva.

PALABRAS CLAVE: Formación de Profesores; Brasil; América Latina; Pedagogías de Inclusión; Educación para la Diversidad.

\begin{abstract}
This is a research that aims to identify formation opportunities for inclusive education in Brazil and in Latin America. It is based on Moscovici's Theory of Social Representations, on Bourdieu's Theory of Action, and on other theoretical references that discuss policies of formation and social inclusion with emphasis on education for diversity. As for the methodology, the following are carried out: Document analysis; interviews with coordinators of Pedagogical courses; and focus groups with students. Content analysis emphasized two analytical dimensions pedagogical dimension of inclusion and dimension of professional responsibility. Finally, it is revealed the need for initial formation in a perspective of inclusive education to enable a more equitable social space for coexistence to guarantee that all have the rights to a fair, equal, and inclusive education.
\end{abstract}

KEYWORDS: Teacher education; Brazil; Latin America; Inclusion Pedagogies; Education for Diversity. 


\section{Introdução}

Os sujeitos sociais compreendem o mundo social que os compreende. (BOURDIEU, 2011, p. 446)

Sabemos que as políticas nacionais de formação de professores são resultantes de processos históricos, que abrangem aspectos sociais, políticos, econômicos, culturais e geram conflitos e consensos, possibilitando influenciar os sujeitos sociais, como diria o autor da epígrafe acima, para que compreendam o mundo social que os compreende. Com base nessas ideias e frente a uma pesquisa que desenvolvemos junto à Oficina Regional de Educação para América Latina e Caribe/OREALC-UNESCO Santiago (2017-2018), referente ao trabalho denominado "Estratégia Regional sobre Docentes"2 (UNESCO, 2018), este texto tem como objetivo identificar oportunidades formativas para a educação inclusiva no Brasil e em países da América Latina.

Nesta direção, os resultados da pesquisa foram obtidos a partir da análise documental (UNESCO, 2005, 2009, 2017, 2018) e do Informe Final sobre a pesquisa realizada no Brasil (ALMEIDA; ABDALLA, 2017). Para análise dos dados, fundamentamo-nos nas teorias bourdieusiana e moscoviciana. Em Bourdieu (2015), consideramos as relações de força, que se traduzem, aqui, em marcos legais, tendências curriculares, e imprimem relações de sentido e de comunicação, produzindo efeitos desencadeadores ou atos de obediência. Em Moscovici (2011), foi possível pensar nos processos de influência e suas modalidades como a conformidade, normatização e inovação, que estão por detrás das práticas voltadas para as pedagogias de inclusão. Além disso, recorremos a autores que tratam de políticas públicas para a educação inclusiva e para a formação docente. Dentre eles, mencionamos: Birgin (2000); Freitas (2002); Aguerrondo (2008); Canen (2008); Darling-Hammond (2012); Abdalla (2019a, 2019b); Brzezinski (2018); e Gatti, Barreto, André e Almeida (2019), entre outros.

De acordo com essas colocações, este artigo tece reflexões sobre os marcos de referência das políticas de formação inicial docente para as pedagogias de inclusão, trata dos padrões e tendências curriculares para a educação inclusiva nos diferentes países da América Latina, e identifica as oportunidades formativas para a educação inclusiva na realidade brasileira. Por fim, apresenta desafios e proposições para que se fundamente o debate sobre as políticas de formação inicial para uma educação inclusiva.

\footnotetext{
${ }^{2} \mathrm{O}$ estudo, em questão, desenvolveu-se em quatro fases: realizou um Estado da Arte sobre políticas docentes (2011-2012); produziu publicações a respeito de experiências relevantes sobre política docente (2012-2013); elaborou um diagnóstico das políticas públicas para a primeira infância (2014-2015); e abordou o ensino das competências para o século XXI e as pedagogias de inclusão, foco deste trabalho.
} 


\section{Marcos de referência de políticas de formação docente sobre as pedagogias de inclusão}

São muitos os desafios que enfrenta a formação inicial docente não só aqui, no Brasil, como nos demais países da América Latina, conforme reforça o Relatório UNESCO (2018). E um dos marcos de referência foi trazer à tona o entendimento da UNESCO (2005) a respeito da inclusão, que a tratou como um processo, que não tem fim, e que busca melhorar formas de responder à diversidade, identificar e remover barreiras, verificar a presença, participação e conquista de todos os estudantes, e minimizar os riscos de marginalização e/ou exclusão.

Ainda, segundo a UNESCO (2009, p. 4), a educação inclusiva tem "por objetivo acabar com a exclusão, que é consequência de atitudes negativas e de uma falta de atenção à diversidade em matéria de raça, situação econômica, classe social, origem étnica, idioma, religião, sexo, orientação sexual e atitudes". Para além dessa intencionalidade, é preciso destacar, ainda, que a pesquisa está de acordo com os Objetivos de Desenvolvimento Sustentável (ODS) e com a Agenda de Educação 2030, que visa, em seu Objetivo 4: "Assegurar a educação inclusiva e equitativa de qualidade, e promover oportunidades de aprendizagem ao longo da vida para todos" (UNESCO, 2017, p. 6).

A par dessas considerações, o Relatório UNESCO (2018) também indica que há substantivas diferenças nos países da América Latina, e que é preciso ter em mente "[...] um conjunto de ações docentes constitutivas de uma "pedagogia da inclusão"' (p. 18). Nesta perspectiva, a UNESCO (2018, p. 23) enfatiza um conjunto de competências para o século XXI, a fim de que se alcance "[...] um contexto de inclusão, em que a criatividade, o pensamento crítico e a inovação se reforçam [...]", propondo, assim, um modelo de ações docentes para uma pedagogia de inclusão, conforme o Quadro 1.

Quadro 1 - Modelo de ações docentes para uma pedagogia de inclusão

\begin{tabular}{|c|c|}
\hline Dimensões & Categorias da Ação Docente \\
\hline Pedagógica & $\begin{array}{l}\text { - Elaboração de planos de ação individuais } \\
\text { - Planificação e adaptação curricular } \\
\text { - Conhecimento pedagógico para um ensino efetivo em contexto de } \\
\text { desvantagens } \\
\text { - Estratégias metodológicas variadas }\end{array}$ \\
\hline $\begin{array}{l}\text { Responsabilidade } \\
\text { Profissional }\end{array}$ & $\begin{array}{l}\text { - Trabalho colaborativo } \\
\text { - Participação da comunidade escolar } \\
\text { - Espaços de reflexão entre profissionais da educação }\end{array}$ \\
\hline
\end{tabular}

Fonte: Secretaria Técnica da Estratégia Regional sobre Docentes (UNESCO, 2018, p. 19). 
Ao introduzir este modelo de ações docentes para uma pedagogia de inclusão, há algumas "afinidades eletivas", diria Bourdieu (2011, p. 225), que traduzem a linguagem política do campo político e que se quer observar na pesquisa. Pois, comenta o autor (2011, p. 429): “O campo político propõe um universo de possibilidades políticas [...] realizadas como o universo das possibilidades possíveis, e, assim, delimitar o universo pensável politicamente" (grifos do autor). Com isso, o modelo indicado, por si só, já constitui um "universo de possibilidades políticas", e que acaba delimitando o "universo pensável politicamente", e, também, a "forma de adaptação" e de "apreensão consciente" às regras do jogo (p. 429). O que gera uma tensão entre o que se propõe, enquanto intenções de pesquisa, e o que se espera alcançar com o modelo de ação (UNESCO, 2018) para uma pedagogia de inclusão. Pensamos também em Moscovici (2012, p. 426), quando afirma que há sempre uma luta de ideias e que "[...] qualquer que seja sua forma, se não resolve sempre o que se propõe, responde necessariamente a um ideal de verdade do qual podemos algumas vezes nos afastar, mas nunca nos separar".

Para responder, então, a este modelo de ações docentes, os pesquisadores vinculados à OREALC-UNESCO realizam uma análise das políticas de educação e de formação inicial de cada um dos países, centrando-se nos marcos legais e considerando as especificidades das regiões e dos currículos. A intenção deste texto é identificar padrões e tendências curriculares com foco nas pedagogias da inclusão, a partir da análise de conteúdo dos informes nacionais dos países envolvidos, e, de acordo com a pesquisa brasileira, analisar as oportunidades formativas dos cursos de Pedagogia da região sudeste.

\section{Dos marcos legais e os conceitos de inclusão}

Ao tratar dos marcos legais, levamos em conta as diferenças culturais dos sete países da América Latina, suas culturas locais e aquelas mais amplas, de modo a compreender como pensam as pedagogias de inclusão. Consideramos, também, conforme o Quadro 2, as instituições formadoras e os conceitos de inclusão, que mostram a diversidade de ideias que estão em jogo. 
Quadro 2 - Instituições formadoras, marcos legais e conceitos de inclusão

\begin{tabular}{|c|c|c|c|}
\hline Países & IES & Marcos Legais & Conceitos de Inclusão \\
\hline Argentina & $\begin{array}{l}\text { Institutos de } \\
\text { Formação } \\
\text { Docente e } \\
\text { universidades }\end{array}$ & $\begin{array}{c}\text { Marco normativo } \\
\text { anterior a } 2015 .\end{array}$ & $\begin{array}{l}\text { Foco na dimensão pedagógica, ao definir a } \\
\text { docência como uma prática centrada no } \\
\text { ensino, que implica organizar e dirigir } \\
\text { situações de aprendizagem, utilizando o } \\
\text { contexto sociopolítico, sociocultural e } \\
\text { sociolinguístico como fonte de ensino. }\end{array}$ \\
\hline Brasil & $\begin{array}{c}\text { Universidades } \\
\text { públicas e } \\
\text { privadas }\end{array}$ & $\begin{array}{l}\text { LDB (1996), Diretrizes } \\
\text { Nacionais para a Formação } \\
\text { Docente (2002 e 2015), } \\
\text { PNE (2014-2024) e outros } \\
\text { documentos. }\end{array}$ & $\begin{array}{l}\text { Atenção à diversidade étnico-cultural. } \\
\text { Postula a acolhida e atenção à diversidade. } \\
\text { Identifica-se um item referente ao respeito e } \\
\text { à valorização da diversidade étnico-racial. }\end{array}$ \\
\hline Chile & $\begin{array}{c}\text { Universidades } \\
\text { públicas e } \\
\text { privadas }\end{array}$ & $\begin{array}{l}\text { Padrões pedagógicos para } \\
\text { os egressos de carreiras de } \\
\text { pedagogias de educação } \\
\text { básica (2011). }\end{array}$ & $\begin{array}{l}\text { Situa-se a inclusão dentro do direito de todos } \\
\text { os estudantes à educação. A diversidade se } \\
\text { reconhece como uma fonte de riqueza para o } \\
\text { desenvolvimento e aprendizagem. Identifica- } \\
\text { se como necessário que os professores se } \\
\text { preparem para estratégias pedagógicas que } \\
\text { contribuam para tornar efetiva a igualdade de } \\
\text { oportunidades e evitar a discriminação. }\end{array}$ \\
\hline Colômbia & $\begin{array}{c}\text { Escolas } \\
\text { Normais e } \\
\text { Universidades }\end{array}$ & $\begin{array}{l}\text { Diretrizes de política } \\
\text { superior inclusiva (2013, } \\
\text { 2016), que fixam } \\
\text { condições para o } \\
\text { credenciamento dos } \\
\text { Programas de Formação } \\
\text { Inicial de Docentes. }\end{array}$ & $\begin{array}{l}\text { Educação inclusiva se relaciona com a } \\
\text { capacidade de melhorar e valorizar a } \\
\text { diversidade, promovendo o respeito a ser } \\
\text { diferente e garantindo a participação da } \\
\text { comunidade dentro de uma estrutura } \\
\text { intercultural dos processos educativos. }\end{array}$ \\
\hline Guatemala & $\begin{array}{c}\text { Universidades } \\
\text { públicas e } \\
\text { privadas e } \\
\text { Escolas } \\
\text { Normais }\end{array}$ & $\begin{array}{l}\text { Políticas educativas do } \\
\text { Conselho Nacional de } \\
\text { Educação (2008). }\end{array}$ & $\begin{array}{l}\text { Fortalecer os processos de escolas inclusivas } \\
\text { para melhorar a qualidade da educação às } \\
\text { pessoas com necessidades educativas } \\
\text { especiais. }\end{array}$ \\
\hline México & $\begin{array}{c}\text { Escolas } \\
\text { Normais e } \\
\text { Universidades }\end{array}$ & $\begin{array}{c}\text { Plano de Estudos para a } \\
\text { Formação de Professores } \\
\text { de Educação Inclusiva } \\
\text { (1997), Plano Nacional de } \\
\text { Desenvolvimento (2001) e } \\
\text { Plano de Estudos para a } \\
\text { Formação de Professores } \\
\text { de Educação Primária } \\
\text { (2012). }\end{array}$ & $\begin{array}{l}\text { O reconhecimento das diferenças individuais } \\
\text { dos alunos é um dos princípios do ensino e } \\
\text { aprendizagem, assumindo o compromisso de } \\
\text { fortalecer práticas específicas para atender à } \\
\text { diversidade e às necessidades educativas } \\
\text { especiais. A partir da década de } 2000 \text {, emerge } \\
\text { a necessidade de fortalecer a atenção } \\
\text { educativa à população indígena. }\end{array}$ \\
\hline Peru & $\begin{array}{l}\text { Institutos } \\
\text { Superiores } \\
\text { Pedagógicos } \\
\text { (IESP) e } \\
\text { Universidades } \\
\text { públicas e } \\
\text { privadas }\end{array}$ & $\begin{array}{l}\text { Regulamento da Lei Geral } \\
\text { de Educação (2003) e Res. } \\
\text { Ministerial n. } 69 \text { (2008). }\end{array}$ & $\begin{array}{l}\text { Reconhece-se a situação de vulnerabilidade } \\
\text { dada por circunstâncias de pobreza, origem } \\
\text { étnica, estado de saúde, deficiência, talento e } \\
\text { superdotação, idade, gênero, risco social e de } \\
\text { outra índole. }\end{array}$ \\
\hline
\end{tabular}

Fonte: elaborado pelas autoras com base nos Quadros 3.1 e 3.4 (UNESCO, 2018, p. 40 e p. 51-53) 
Segundo a UNESCO (2018), na Argentina, a inclusão tem uma perspectiva exclusivamente pedagógica, com o foco nas necessidades educativas especiais. No Brasil, a LDB no. 9.394/96 (BRASIL, 1996), no art. 59, busca assegurar o atendimento às necessidades dos alunos com deficiência e aceleração de estudos aos superdotados. Quanto à formação docente, a Res. CNE/CP n ${ }^{\circ}$ 1/2002 (BRASIL, 2002), ao estabelecer as DCN para a Formação de Professores da Educação Básica, define que as instituições prevejam uma formação docente voltada para a diversidade, contemplando conhecimentos sobre as especificidades dos alunos. Em 2004, a Res. n 1/2004 (BRASIL, 2004) institui as DCN para a Educação das Relações Étnico-Raciais e para o Ensino de História e Cultura Afro-Brasileira e Africana. Mais tarde, a Lei n ${ }^{\circ}$ 13.005/2014, referente ao PNE (BRASIL, 2014), destaca princípios quanto ao respeito aos direitos humanos e à valorização da diversidade e da inclusão. Princípios estes que também são valorizados pela Res. CNE/CP 2/2015, ao definir as DCN para a formação inicial e continuada de professores (BRASIL, 2015).

No Chile, ocorreu um movimento de valorização da diversidade e da inclusão similar ao da Argentina e do México, que foi impulsionado pelos movimentos sociais e culturais que ocorreram a partir de 1990 e que culminaram em uma lei, de 2016, sobre inclusão nas instituições escolares. E, na Colômbia, na década de 2010, a partir das diretrizes, desenvolveu-se o conceito de inclusão multidimensional que incorpora a valorização da diversidade e altera a dimensão social da inclusão.

$\mathrm{Na}$ Guatemala, as políticas educativas, posteriores ao ano de 2000, enfatizam o acesso ao sistema dos estudantes com deficiência. Enquanto que no México destacam-se questões em torno da multiculturalidade, existindo uma linha formativa que lida com o bilinguismo. E, no Peru, identificam-se diretrizes, posteriores a 2000, associadas às pedagogias para a inclusão, e que se associam às questões de vulnerabilidade educativa, definindo normas para assegurar o acesso de estudantes com deficiência.

Se tomarmos os marcos legais, observamos que há diferenças nestes países, e que exercem "relações de força e de sentido" conforme Bourdieu (2015, p. 228). Para este autor, tais relações são inseparáveis das "relações de comunicação" e produzem "efeitos de crença", que demarcam "atos de submissão e de obediência" (p. 229). Para Moscovici (2011), trata-se de compreender um "processo de influência", que está em desenvolvimento, especialmente, por delinear uma certa "normatização", a fim de "[...] impedir o desacordo em relação ao esquema de referência" (p. 182). Dessa forma, este processo de influência retrata atos de submissão e de obediência, aprofundando atos de normatização, tais como os padrões e tendências curriculares a seguir. 


\section{Padrões e tendências curriculares para as pedagogias de inclusão}

Em síntese, o documento da UNESCO (2018) traz um resumo dos padrões curriculares, identificando três categorias de análise, conforme o Quadro 3.

Quadro 3 - Resumo dos padrões curriculares: Pedagogias para Inclusão

\begin{tabular}{|c|c|c|}
\hline \multicolumn{3}{|c|}{ Padrões curriculares detectados nos documentos das instituições } \\
\hline Visões e ênfases & $\begin{array}{c}\text { Localização ou } \\
\text { transversalização }\end{array}$ & $\begin{array}{c}\text { Prática como espaço } \\
\text { formativo }\end{array}$ \\
\hline $\begin{array}{l}\text { Detectam-se visões distintas e } \\
\text { focos específicos: } \\
\text { - Desigualdades sociais } \\
\text { - Povos nativos e } \\
\text { interculturalidade } \\
\text { - Ruralidade } \\
\text { - Necessidades Educativas } \\
\text { Especiais (NEE) } \\
\text { - Contextos de desvantagem } \\
\text { - Etnia-rasa }\end{array}$ & $\begin{array}{l}\text { - Cursos específicos sobre } \\
\text { temas de diversidade e } \\
\text { inclusão. } \\
\text { - Caráter distribuído ou } \\
\text { transversal do tema em todo o } \\
\text { currículo. }\end{array}$ & $\begin{array}{l}\text { Experiências de prática em que } \\
\text { se promove a criação de relações } \\
\text { comunitárias baseadas nos } \\
\text { princípios de equidade e } \\
\text { inclusão. }\end{array}$ \\
\hline
\end{tabular}

Fonte: dados obtidos e alterados junto ao documento "Estratégia Regional sobre Docentes" (UNESCO, 2018, p. 82).

Quanto à primeira categoria - Visões e ênfases da inclusão nos currículos -, destacamos que as visões e ênfases formativas para a inclusão são diferentes nos países. Para Argentina, a escola deverá assumir uma visão sociocrítica a respeito das desigualdades sociais, fazendo com que seus professores sejam agentes transformadores. Já, o México trata de políticas educativas para atender à diversidade étnica própria do país, assegurando aos professores o ensino bilíngue e uma trajetória formativa intercultural.

Por outro lado, as instituições formativas da Colômbia destacam duas ênfases para a inclusão: formar professores não excludentes, em uma lógica que garanta os direitos humanos; e refletir sobre uma inclusão que assuma um compromisso social e político. No caso do Peru, o foco se concentra no trabalho curricular, colaborativo e com a comunidade, dentro de um enfoque de diversidade relacionado à interculturalidade. E, no Brasil, identificam-se temas de diversidade e de inclusão, que dão conta de visões conceituais distintas, considerando: as diversidades étnico-raciais, questões de gênero, de classes sociais, de necessidades especiais, opções sexuais etc.

Quanto à segunda categoria - Localização versus transversalização curricular -, o documento trata da existência de cursos específicos, que promovem, em seus currículos, os temas da diversidade e inclusão, considerando-os como espaços formativos necessários. E isso ocorre em, pelo menos, seis dos sete países: Brasil, Colômbia, Chile, Guatemala, México e Peru. No currículo da Argentina, esta temática não aparece, de 
forma explícita, pois o que se propõe é que se tenha uma visão mais ampliada e/ou transversal, e que se usem as tecnologias digitais neste sentido.

Em relação à terceira categoria - As práticas como espaços formativos para a inclusão-, o documento menciona casos de dois países: Colômbia e Argentina. No primeiro, revelam-se três modalidades de prática: responsabilidade social, buscando sensibilizar e conscientizar docentes para os contextos vulneráveis; pedagógicas, que têm a ver com as competências próprias da docência; e profissionais, que desenvolvem competências específicas referentes aos saberes disciplinares de cada licenciatura. Já, na Argentina, desenvolvem-se espaços de prática baseados na inclusão e na equidade, assumindo a docência na educação com um perfil profissional que enfrenta as desigualdades sociais.

Os marcos legais e os padrões curriculares levam-nos a dar especial valor, sobretudo, às práticas, tratadas como espaços formativos para a inclusão, e às oportunidades formativas nesta direção.

\section{Das oportunidades formativas para a educação inclusiva: a pesquisa brasileira}

Os dados da pesquisa (ALMEIDA; ABDALLA, 2017) foram coletados em três Instituições de Ensino Superior (IES) da região sudeste, que concentra $44 \%$ do total nacional de cursos de Pedagogia. Foram selecionadas duas universidades públicas (estadual e federal) e uma privada, dada à representatividade de suas matrículas. Tais instituições serão assim nomeadas: IES Pública Federal, IES Pública Estadual e IES Privada. Destacamos, ainda, que este estudo indicará apenas pistas sobre se e como o tema da inclusão integra o itinerário formativo do futuro professor.

Tivemos acesso aos Projetos Pedagógicos de Cursos (PPC) dessas instituições, e realizamos entrevistas, com coordenadores de curso e professores formadores, e grupos focais com os estudantes dos dois últimos semestres da Pedagogia. O Quadro 4, a seguir, traz um retrato a respeito da coleta de dados junto aos formadores e estudantes. 
Quadro 4: Entrevistas e grupos focais por IES

\begin{tabular}{|c|l|l|}
\hline IES & \multicolumn{1}{|c|}{ Formadores } & \multicolumn{1}{|c|}{ Estudantes } \\
\hline $\begin{array}{c}\text { IES } \\
\text { Fública }\end{array}$ & $\begin{array}{l}\text { Entrevistadas com duas Professoras } \\
\text { Formadoras atuantes no Curso de } \\
\text { Pedagogia e que foram Coordenadoras } \\
\text { do curso nas gestões anteriores }\end{array}$ & $\begin{array}{l}\text { Dois grupos focais, totalizando dez } \\
\text { estudantes dos últimos semestres do } \\
\text { curso: um com cinco estudantes } \\
\text { (noturno); e outro com cinco } \\
\text { (matutino). }\end{array}$ \\
\hline IES & $\begin{array}{l}\text { Entrevistas com a Coordenadora de } \\
\text { curso e com a Vice Coordenadora, } \\
\text { também responsável pelos estágios. }\end{array}$ & $\begin{array}{l}\text { Um grupo focal com cinco estudantes } \\
\text { dos últimos semestres do curso (dois do } \\
\text { noturno e três do matutino). }\end{array}$ \\
\hline Estadual \\
\hline IES & $\begin{array}{l}\text { Entrevista com duas Coordenadoras da } \\
\text { gestão acadêmica, responsáveis pelo } \\
\text { PPC e por sua implementação nas } \\
\text { unidades de ensino, que oferecem este } \\
\text { curso nas modalidades presencial e a } \\
\text { distância. }\end{array}$ & $\begin{array}{l}\text { Um grupo focal realizado com sete } \\
\text { estudantes (noturno), matriculados no } \\
\text { unidade localizada na cidade de São } \\
\text { Paulo. }\end{array}$ \\
\hline
\end{tabular}

Fonte: elaborado pelas autoras.

Nas entrevistas e também no grupo focal, foi apresentado o delineamento teóricometodológico da pesquisa, considerando duas questões desencadeadoras: (i) Se e como o curso de Pedagogia cria oportunidades de aprender a trabalhar em contextos de maior dificuldade educacional (níveis de desempenho diversos, com distintas culturas, em condições de pobreza ou com condições educativas especiais?); (ii) $S e$ os professores que se formam, nesta instituição, estão bem preparados para o exercício da docência? Essas perguntas permitiram que os participantes relatassem suas percepções sobre o itinerário formativo do curso quanto à inclusão, destacando: as práticas formativas, os componentes curriculares e as vivências, que favoreceram a formação profissional.

A análise dos dados exigiu uma organização em duas etapas. Na primeira, elaborar a análise preliminar e sistematizar os dados das entrevistas e do grupo focal de cada instituição. Na segunda, sistematizar os dados das três instituições, buscando ater-se aos significados dos dados obtidos, na tentativa de identificar relações entre os achados em cada IES, bem como as relações entre os relatos e os objetivos de pesquisa.

Também, dois aspectos foram relevantes aos objetivos do estudo: considerar o que os formadores e estudantes fazem com as atividades materiais e simbólicas, desenvolvidas no locus de formação; e identificar as práticas formativas que favorecem (ou não) a atuar em um contexto organizacional complexo (a Escola), em uma sociedade em constante transformação, a fim de promover um ensino equitativo.

$\mathrm{Na}$ análise comparativa, consideramos as especificidades das instituições, a cultura administrativa e profissional, bem como as práticas de formação, o espaço universitário, as tensões e os impasses próprios da formação inicial. Moscovici (2012, p. 231) diria: “[...] temos, de um lado, relações operatórias comuns, e, de outro, relações 
normativas que controlam, verificam, dirigem as primeiras". Essas relações de "força, de sentido e de comunicação" se desdobram em "efeitos de crença", conforme Bourdieu (2015).

\section{Dimensão pedagógica da inclusão}

Em relação à dimensão pedagógica da inclusão, iniciamos por destacar que, nas três IES, prevalece a oferta de disciplinas obrigatórias e eletivas, que dizem respeito, principalmente, à educação especial e às questões étnico-raciais, de gênero, sexual e religiosa. A IES Pública Estadual é a única que oferece um rol de oito disciplinas (obrigatórias e eletivas), que tratam de questões correlatas à inclusão. Observamos, assim, que o lugar da dimensão pedagógica da inclusão tem por base o desenvolvimento de práticas pedagógicas que estão diluídas no currículo concebido e no currículo vivido.

A dimensão pedagógica da inclusão, tendo em vista a formação para a educação inclusiva, foi analisada a partir das categorias detalhadas no Quadro 5. Essas categorias orientaram a análise dos currículos de formação e conduziram as entrevistas com os coordenadores dos cursos de Pedagogias e os grupos focais com estudantes. Tais categorias aparecem tangenciadas nas práticas formativas, especialmente nas disciplinas de didática específica, metodologias de ensino e no estágio curricular supervisionado.

Quadro 5 - Categorias de ação da dimensão pedagógica

\begin{tabular}{|c|l|}
\hline Categorias de ação & \multicolumn{1}{c|}{ Detalhamento } \\
\hline $\begin{array}{c}\text { Elaboração de planos de } \\
\text { ação individuais }\end{array}$ & $\begin{array}{l}\text { Formação em estratégias de avaliação e o uso da informação para } \\
\text { que os futuros professores sejam capazes de adaptar os programas } \\
\text { aos diversos modos e ritmos de aprendizagem. }\end{array}$ \\
\hline $\begin{array}{c}\text { Planificação e adaptação } \\
\text { curricular }\end{array}$ & $\begin{array}{l}\text { Adaptação curricular para responder às necessidades de } \\
\text { aprendizagem dos estudantes e consciência de que a gestão do } \\
\text { currículo é a chave para o reconhecimento da diversidade. }\end{array}$ \\
\hline $\begin{array}{c}\text { Conhecimento } \\
\text { pedagógico para um } \\
\text { ensino efetivo em } \\
\text { contexto de desvantagens }\end{array}$ & $\begin{array}{l}\text { Conhecimento dos contextos de desvantagem e pobreza e seus } \\
\text { efeitos sobre as características dos que aprendem os métodos e as } \\
\text { relações sociais requeridas nos respectivos contextos para que } \\
\text { haja um ensino efetivo. }\end{array}$ \\
\hline $\begin{array}{c}\text { Estratégias metodológicas } \\
\text { variadas }\end{array}$ & $\begin{array}{l}\text { Que sejam atrativas, interativas e que fomentem e promovam o } \\
\text { apoio dos colegas, uma atitude de vida baseada no saber escutar, } \\
\text { respeitar, participar e interpretar crítica e construtivamente a } \\
\text { realidade social. }\end{array}$ \\
\hline
\end{tabular}

Fonte: Elaborado pelas autoras, com alterações relacionadas às informações contidas no documento "Estratégia Regional sobre Docentes” (UNESCO, 2018, p. 22-23).

Na percepção das Coordenadoras, Formadoras e estudantes das IES Públicas, a educação inclusiva é abordada, principalmente, em uma perspectiva política, cultural e 
social, com base no direito à educação de qualidade, em defesa do direito de todos os alunos de estarem aprendendo e participando, sem nenhum tipo de discriminação. A fala da ex-Coordenadora do Curso de Pedagogia da IES Pública Federal ilustra essa questão:

A questão das minorias sociais é muito trabalhada aqui como a questão da desigualdade social, inclusão social, indo para além da questão de deficiência. Isso tem acento no curso e não é um acento que se deu por acaso, é um acento de luta!

Esse depoimento explicita a preocupação das formadoras, especialmente da IES Pública Federal, em colocar em pauta, no PPC da Pedagogia, o tema da inclusão com ênfase nas diferenças de classe social, idade, gênero, capacidade intelectual, raça, interesses entre os alunos, para eliminar as diferenças e melhorar a qualidade do ensino nas escolas. Por outro lado, as formadoras reconhecem a pouca ênfase dada à dimensão pedagógica da inclusão, também observada pelos futuros professores.

Apesar da reconhecida contribuição da didática específica, metodologias de ensino e do estágio curricular supervisionado, os futuros professores, especialmente das IES Públicas, relatam suas dúvidas sobre terem desenvolvido ou não conhecimentos pedagógicos, que permitam, por exemplo, ensinar em contextos desfavorecidos ou elaborar planos de ação que atendam aos diferentes estilos de aprendizagem e necessidades dos alunos. Durante a discussão no grupo focal da IES Pública Federal, uma das estudantes coloca para o grupo uma situação hipotética: "Imaginamos eu chegar em uma sala de aula com crianças de sete anos e não necessariamente são todas da mesma classe social, tem as mesmas experiências, as mesmas trajetórias e eu teria que ensinar cada uma delas, teria que pensar de uma outra forma, mas qual? Como?". Relata que, no curso, "as atividades propostas são muito lineares" e sugere que os casos e situações de sala de aula deveriam ser mais explorados nas disciplinas.

Na IES Pública Estadual, os estudantes compartilham da mesma inquietação ao reconhecerem e valorizarem a sólida formação teórica: "Hoje em dia, eu vejo que foi fundamental eu ter essa parte toda teórica, para sair daqui e atuar do jeito que eu acredito ser o certo!". No entanto, também avaliam as limitações do curso em relação à prática docente propriamente dita: "a gente não aprende a ensinar nos anos iniciais".

As Coordenadoras e Formadoras das IES Públicas também analisam as limitações e possibilidades do curso de Pedagogia quanto à formação para promover a educação inclusiva, que pressupõe uma maior articulação entre as dimensões teórica e prática. As Formadoras da IES Pública Federal, em diferentes momentos da entrevista, colocam em evidência os desafios que limitam o mandato do "ensinar a ensinar" no contexto da formação inicial, bem como as ações delineadas para as disciplinas e para o estágio para 
a sua superação. Entendem, assim, que o curso de Pedagogia precisa equilibrar as dimensões teórica e prática, o que implica, segundo elas, o enfrentamento de tensões.

Como o ponto forte do curso é a formação política, a Formadora da IES Pública Federal explica que é difícil fazer "o contraponto de que não basta a dimensão política estar muito forte, mas a dimensão técnica e humana precisam também ser, de alguma maneira, trabalhadas fortemente, porque se não os alunos depois chegam na sala de aula e desistem da docência e isso tem acontecido". Sua preocupação é de que "o ponto forte vai se tornando mais forte e o ponto fraco vai ficando mais fraco e isso precisa ser enfrentado na reformulação curricular do curso".

Já as Formadoras da IES Pública Estadual, mesmo sem deixar de dar destaque à importância da relação entre teoria e prática no curso, entendem que a sólida formação teórica, a que os estudantes têm acesso durante o curso, permite que analisem criticamente os contextos em que vão atuar e que façam escolhas pedagógicas acertadas.

Comentam, a seguir, sobre a principal identidade do curso de Pedagogia:

A principal identidade do curso de Pedagogia se pauta na formação de um profissional, um pedagogo que tenha a reflexão da sua prática, que consiga estabelecer essa relação entre a sua prática, os elementos que a fundamentam e, ao mesmo tempo, a compreensão da sua realidade, da realidade educacional. (Coord. e Profa. da IES Pública Estadual)

Além disso, a Coordenadora relata que o corpo docente tem recorrentemente discutido os rumos do curso de Pedagogia e que o projeto de curso foi revisto em diferentes momentos, antes e depois da aprovação da Resolução CNE/CP n ${ }^{\circ}$ 01/2006 (BRASIL, 2006). Destaca, neste sentido, a influência freiriana no curso, bem como da Anfope $^{3}$, e ressalta que a sua marca principal é "[...] possibilitar a formação de um profissional pedagogo que compreenda a relevância da sua prática e, ao mesmo tempo, os elementos que a constituem e, também, compreender os meios ou mecanismos de problematizá-los mediante situações do cotidiano ou situações-problema". Também, revela que a mudança de foco na formação do pedagogo, antes voltada para a formação do especialista, agora, volta-se para a docência, o que trouxe para o curso, "[...] uma relação direta com a escola; ou seja, o estudante compreende a escola como um todo e não de forma fragmentada, como anteriormente". Comenta, ainda, que o PPC em vigência, "[...] mesmo com as adequações que foram sendo realizadas por conta da

\footnotetext{
${ }^{3}$ É preciso destacar que, nas IES públicas (federal e estadual), os padrões curriculares do curso de Pedagogia seguem os princípios da Anfope, fundamentados na Base Comum Nacional, tais como: sólida formação teórica e interdisciplinar; unidade entre teoria e prática; gestão democrática; compromisso social, político e ético; trabalho coletivo e interdisciplinar, concepção de formação continuada; e avaliar permanentemente os cursos de formação dos profissionais de educação (BRZEZINSKI, 2018).
} 
legislação nacional, e em particular da estadual, ainda mantém essa característica: a formação do pedagogo que atue na escola pública!”.

Ambas as Coordenadoras da IES Pública Estadual compartilham da ideia de que os futuros professores saem do Curso de Pedagogia "muito mais preparados para as diversidades que eles vão encontrar do que munidos de técnicas e métodos para trabalhar em sala de aula". Uma das Coordenadoras entende que o curso oferece as condições necessárias para o exercício docente e que os estudantes terão "condições de buscar técnicas e métodos, de se instrumentalizarem, saber buscar em determinadas fontes qual a melhor forma de trabalhar com grupos heterogêneos". Para ela, o estudante é preparado para trabalhar com a diversidade em sala de aula, inclusive, de "lidar com essa diversidade de maneira a não abafar uns e elevar outros". Pondera, ainda, que, diferentemente de "outras instituições, que têm uma preocupação formativa com a prática desde o primeiro ano até o último", a preocupação do Curso de Pedagogia de sua IES "tem sido desconstruir muitas coisas para poder ter subsídios de construção".

Quanto aos estudantes das instituições públicas, estes revelam que o curso os estimula a refletirem, a analisarem e a avaliarem criticamente a sociedade e, em especial, a educação, a escola e a sala de aula. Um deles relata que: "[...] no curso nunca foi uma ideia de como eu devo dar aula, mas sim o que eu devo fazer para que a sociedade seja melhor através da escola" (Estudante da IES Pública Estadual).

Já na IES Privada, tanto as Coordenadoras quanto as estudantes relatam que o curso promove várias situações, em que foram oportunizadas atividades relacionadas ao aprendizado da docência. Os estudantes explicam que o PPC do Curso prevê disciplinas específicas de inclusão e que o destaque ao trabalho com e para a diversidade é transversal em várias disciplinas conforme o depoimento de um deles: "Na disciplina de Currículo, a professora bate bem na questão da diversidade. Sempre chama a atenção de que é preciso contextualizar, tentar atender a todo mundo, às demandas, às diferenças" (Estudante da IES Privada).

Essas declarações são ilustrativas de que os estudantes identificam no curso e, especialmente, na postura dos professores: um cuidado com a formação docente para a diversidade. Também, essas ideias são partilhadas pelas demais estudantes, reforçando esse cuidado dos docentes com o aluno, com a sua história e suas necessidades. Ainda, deram exemplos de situações em que foram estimuladas a elaborar material didático e desenvolver projetos que fossem inclusivos.

Entretanto, cabe ressaltar que os estudantes pouco falaram sobre a fundamentação teórica, que subsidia as escolhas no processo de elaboração das aulas, materiais didáticos e projetos ou sobre como percebem a relação entre teoria e prática. As falas são, 
principalmente, sobre situações práticas e, em sua maioria, são breves e sem uma elaboração argumentativa sobre a situação relatada.

Por fim, quanto ao estágio curricular supervisionado, desenvolvido pelas três IES, observamos que este apresenta limitações como a dificuldade de acompanhamento efetivo do estágio e a pouca integração com as escolas. Contudo, ele é considerado, principalmente pelos estudantes, como um espaço rico de possibilidades para trabalhar as questões relativas à diversidade e à inclusão, conforme o registro a seguir:

[...] a gente conversou muito e eu vi experiências sobre os diversos alunos, não só com relação às deficiências, mas com relação às diferentes etnias, aos diferentes gostos, diferentes saberes, aptidões; enfim, eu acho que isso foi muito debatido e não tem como o estágio. (Estudante da IES Pública Estadual)

Além disso, os estudantes destacam a incoerência e inconsistência entre as discussões teóricas, as situações de formação e de exercício profissional, que vivenciam nos estágios, e chamam a atenção para questões que envolvem a responsabilidade profissional, que será discutida na dimensão a seguir.

\section{Dimensão de responsabilidade profissional}

A dimensão de responsabilidade profissional nas práticas formativas foi analisada a partir das categorias detalhadas no Quadro 6, a seguir. Consideramos, também, que essa dimensão está pouco explicitada nos PPC e nas verbalizações das Coordenadoras, Formadoras e dos estudantes das três IES.

Quadro 6 - Categorias de ação da dimensão de responsabilidade profissional

\begin{tabular}{|c|l|}
\hline Categorias de ação & \multicolumn{1}{|c|}{ Detalhamento } \\
\hline $\begin{array}{c}\text { Trabalho } \\
\text { colaborativo }\end{array}$ & $\begin{array}{l}\text { Cultura de trabalho comum e uma vontade coletiva que envolva a } \\
\text { todos os membros da comunidade educativa. Modelos de trabalho } \\
\text { baseados na colaboração e processos pedagógicos inclusivos que } \\
\text { permitam a todos contribuir equitativamente. }\end{array}$ \\
\hline $\begin{array}{c}\text { Participação da } \\
\text { comunidade escolar }\end{array}$ & $\begin{array}{l}\text { Acolhida, afeto, acompanhamento e dinâmicas de convivência, com } \\
\text { especial integração aos estudantes e à formação contra todo tipo de } \\
\text { discriminação social e cultural. }\end{array}$ \\
\hline $\begin{array}{c}\text { Espaços de reflexão } \\
\text { entre profissionais } \\
\text { da educação }\end{array}$ & $\begin{array}{l}\text { Refletir coletivamente sobre os próprios preconceitos e } \\
\text { estigmatizações, que se dão no interior dos estabelecimentos escolares, } \\
\text { para analisar situações que afetam as aprendizagens de alguns } \\
\text { estudantes e as estratégias e metodologias mais efetivas para abordá- } \\
\text { las. }\end{array}$ \\
\hline
\end{tabular}

Fonte: Elaborado pelas autoras, com alterações relacionadas às informações contidas no documento “Estratégia Regional sobre Docentes" (UNESCO, 2018, p. 22-23). 
Nos PPC, as IES indicam a necessidade de se promover a convivência democrática, facilitando as relações de cooperação, colaboração e corresponsabilidade entre contexto educacional, a família e a comunidade. Nesta perspectiva, consideram, também, a necessidade de se implementar formas de gestão democrática, levando em conta que aprender a trabalhar de modo colaborativo, valorizar e potencializar espaços de reflexão e estabelecer uma relação positiva com a comunidade escolar são aprendizados que podem ser desenvolvidos ao longo do curso, no contexto das disciplinas, dos estágios, dos projetos de extensão e de iniciação à docência, e na pesquisa. Essas experiências diversificadas favorecem ao desenvolvimento da responsabilidade profissional e são valorizadas pelos futuros professores. No entanto, a intencionalidade dessa formação, na perspectiva da educação inclusiva, não está dada nos PPC e nas verbalizações.

Apesar de a ideia de inclusão, em um sentido amplo e, portanto, para além das necessidades educativas especiais, encontrar eco nas práticas formativas, o equilíbrio entre a formação política e pedagógica, tendo em vista a educação inclusiva, é frágil. Os estudantes demonstraram que possuem clareza dos mecanismos escolares que reproduzem as desigualdades e de sua responsabilidade profissional em fazer valer o direito de todos à educação de qualidade, destacando:

Tem muito essa questão da responsabilidade social. Eu tenho isso muito forte em minha formação: olhar a educação de uma forma responsável socialmente. (IES Pública Estadual)

[...] o curso fez uma enorme diferença na minha visão, de como eu enxergo a escola, de como eu entendo o meu aluno, de como eu vejo as relações entre a sociedade e a escola. (IES Pública Federal)

Os relatos deixam claro que o percurso formativo proposto pelas IES Públicas promove uma discussão do fenômeno educativo, considerando as relações entre educação e sociedade a partir de uma reflexão teórica, crítica e transformadora. O que favorece também o desenvolvimento do pensamento crítico e a tomada de consciência de seu compromisso político-ideológico como professor e cidadão.

As coordenadoras da IES Púbica Estadual também ressaltam a qualidade do curso quanto à formação política. Entendem que o curso oferece as condições necessárias para o exercício docente e que os estudantes, segundo a Coordenadora de Estágio, terão "condições de buscar técnicas e métodos, de se instrumentalizarem, saber buscar em determinadas fontes qual a melhor forma de trabalhar com grupos heterogêneos". Para ela, eles estão sendo preparados para trabalhar com a diversidade em sala de aula, inclusive, de "lidar com essa diversidade de maneira a não abafar uns e elevar outros".

Os estudantes das IES Públicas e da IES Privada não só reconhecerem o potencial formativo do curso, como estão conscientes de que ainda sabem pouco sobre como: 
planejar o ambiente de aprendizagem, orquestrar as interações, fazer com que todos participem, promover a responsabilidade compartilhada e intervir para diminuir as desigualdades na sala de aula. E, mesmo não se sentindo preparados para o exercício da docência, especialmente em contextos desfavorecidos, acreditam que estão preparados para se prepararem e conscientes do esforço profissional e pessoal que terão que empreender para promoverem um ensino justo, equitativo, como afirmam a seguir:

[...] o curso abriu o leque de visões, de percepções que eu não tinha antes, principalmente, de questionar. A gente aprendeu a problematizar tudo, a questionar, se perguntar e a perguntar. (Estudante da IES Federal)

Bom, eu acredito que, nesse tempo em que eu passei na IES, ela me ofereceu um suporte teórico, de conhecimento, uma possibilidade de enxergar o mundo, a realidade, de uma forma muito mais ampla do que eu tinha. (Estudante da IES Pública Estadual).

[...] A gente sai daqui preparada para saber como tentar lidar com aquilo. Se eu não sei, se a gente não sabe, como a gente pode tentar trabalhar com aquilo? Ou se eu não consigo, onde eu posso saber? Onde a gente pode procurar? (Estudante da IES Privada)

Porém, é certo que algumas lacunas formativas terão implicações para o trabalho docente dos futuros professores e, consequentemente, para a aprendizagem dos alunos. Ainda, é importante lembrar que as situações de estágio favorecem a mobilização da dimensão pedagógica da inclusão, bem como da responsabilidade profissional. São muitas as possibilidades de o futuro professor não só compreender a complexidade e os desafios do ensino em contextos diversos, inclusive os desfavorecidos, como também conhecer e analisar as possibilidades de atuação do docente e de toda a equipe escolar, tendo em vista a educação inclusiva.

Com efeito, podemos afirmar que a colaboração, a cidadania e a responsabilidade social são devidamente consideradas na formação do profissional das IES analisadas. Ainda, nos diferentes Projetos, são desenvolvidas metas e estratégias para a participação da comunidade escolar, por meio de trabalhos colaborativos. O que pode indicar, também, uma gestão inclusiva, que enfatiza uma dimensão de responsabilidade profissional.

Frente às desigualdades de oportunidades sociais, culturais e educacionais, são notórias as diferenças de perfil entre os estudantes das IES Públicas e da IES Privada retratadas nos grupos focais em relação à capacidade argumentativa, de encadeamento de ideias, de levantamento de hipóteses e proposições, e em relação ao posicionamento crítico. 


\section{Reflexões finais: desafios e proposições}

Não há dúvida de que a revolução simbólica supõe sempre uma revolução política... (BOURDIEU, 1998, p. 77)

Este texto, com o objetivo de identificar as oportunidades formativas para a educação inclusiva no Brasil e em países da América Latina, procurou discutir, primeiro, as políticas de formação inicial de cada um dos países, no que diz respeito aos marcos legais para as pedagogias de inclusão, considerando as especificidades de cada região. Em um segundo momento, foram analisados os padrões e as tendências curriculares, colocando o foco nas visões e ênfases da inclusão nos currículos, na localização versus transversalização curricular e nas práticas como espaços formativos para a inclusão. E, em um terceiro momento, privilegiou-se uma análise em torno das oportunidades formativas, procurando desvelar as representações sociais dos agentes/atores, tendo em vista as práticas dos currículos vivenciadas na perspectiva de uma educação inclusiva.

Nesta direção, observamos que os marcos legais e os padrões curriculares descritos apresentam algumas "amarrações", como diria Moscovici (2011), e/ou implicações, porque: $1^{a}$ trata-se de políticas de formação que criam normas, que reforçam os processos de influência e as representações sociais a respeito, via marcos legais, padrões curriculares e/ou modelos de ação, no caso das pedagogias de inclusão; $2^{\circ}$ desenvolvem modalidades específicas de influência, pois as instituições e seus sujeitos envolvidos na implementação das políticas passam por momentos de conformidade, de normatização e de inovação à medida em que vivenciam experiências no enfrentamento dos desafios para uma educação mais inclusiva; e $3^{\circ}$ demandam processos de negociação diferentes para cada um dos países, tendo em vista suas realidades específicas.

Além disso, tais implicações revelam, como afirmaria Bourdieu (2015, p. 228), relações de força, de sentido e de comunicação, que são, ao mesmo tempo, "relações ou formas simbólicas", que geram "efeitos desencadeadores de crença". Como o próprio Bourdieu (2015, p. 230) enfatiza: "Estas formas simbólicas são os princípios de construção da realidade social: os agentes sociais não são simplesmente partículas movidas pelas forças físicas, são também agentes com conhecimentos que são portadores das estruturas cognitivas". E, como ele próprio afirma: "Não há dúvida de que a revolução simbólica supõe sempre uma revolução política” (BOURDIEU, 1998, p. 77).

Compreendemos, assim, que há alguns desafios a serem enfrentados. O primeiro deles é que a formação inicial retrata tendências de heterogeneidade e desigualdade no magistério, o que faz com que este quadro apresente implicações para os cursos de formação, que precisam analisar com mais atenção os perfis e as necessidades dos estudantes que ingressam nos cursos de Pedagogia e, consequentemente, reestruturam as práticas formativas. O segundo é que os discursos apregoam uma educação inclusiva 
como direito de todos; entretanto, as universidades e/ou escolas, em sua maioria, não oferecem tempo e espaços, para que, de fato, possa se desenvolver um ensino mais equitativo. O terceiro evidencia que, na formação para a docência, ainda existe uma tensão entre a ênfase na formação teórica e/ou na formação prática, especialmente no que diz respeito às práticas que contemplem as pedagogias de inclusão. Entretanto, um dos maiores desafios que as instituições formativas necessitam enfrentar é de natureza ética. E, nesta perspectiva, é preciso que a formação docente tenha reflexos diretos sobre a educação escolar das novas gerações em um contexto de mudanças sociais complexas, e que as instituições formativas assumam seu compromisso social com a educação.

Por outro lado, estes desafios também anunciam proposições, que apontam para a necessidade de se: $1^{\circ}$ ampliar o fomento de políticas públicas de inserção docente, visando a apoiar estudantes de Pedagogia e demais licenciaturas, para que estimulem experiências diversificadas, bem como favoreçam a integração entre educação superior e a educação básica; $2^{\circ}$ equilibrar, no desenho curricular dos cursos de Pedagogia, a formação política e pedagógica, tendo em vista a educação inclusiva e a redução das desigualdades na sala de aula, especialmente em contextos desfavorecidos; e $3^{\circ}$ desenvolver ações de formação, que fortaleçam trabalhos colaborativos e a responsabilidade profissional, de forma a socializar os saberes e as experiências ao lidar, especialmente, com a educação inclusiva voltada para a diversidade.

Com efeito, tudo isso significa abrir possibilidades para uma convivência equânime, em que todos tenham seus direitos garantidos. E, neste caminho, há necessidade da formação inicial ser pensada em uma perspectiva de educação inclusiva, a fim de que se possibilite um espaço social de convivência mais equânime na direção de garantir os direitos de todos a uma educação justa, igualitária e inclusiva.

\section{Referências}

ABDALLA, M. F. B. Das políticas educacionais, representações e práticas: repensando a formação e a profissionalização docente para a diversidade cultural e a inclusão. In: ENS, R. T.; OGLIZRI, C.R.N.; RENNER, R.L. (Org.). Do diálogo entre políticas e representações sociais às práticas. Curitiba, CRV, 2019a, p. 37-59.

ABDALLA, M. F. B. O PNE e as políticas de formação e valorização docente em termos de crise. In: LINO, L. A.; NAJJAR, J. (Org.). Planos de Educação, democracia e formação: desafios em tempos de crise. Curitiba, Appris, $2019 \mathrm{~b}$.

AGUERRONDO, I. Revisar el modelo: un desafío para lograr la inclusión Revista Perspectivas 145, v. 38, n, 1, marzo de 2008. 
ALMEIDA, P. C. A.; ABDALLA, M. F. B. Informe Final. Formação inicial de docentes para os anos iniciais do ensino fundamental na perspectiva das competências para o século 21 e da inclusão. Brasil, UNESCO-OREALC, 2017.

BIRGIN, A. La docencia como trabajo: la construcción de nuevas pautas de inclusión y exclusión. In: GENTILI, P.; FRIGOTTO, G. (Orgs.). La ciudadanía negada: políticas de exclusión en la educación y el trabajo. Buenos Aires, FLACSO, 2000.

BOURDIEU, P. A economia das trocas simbólicas. 5a ed. São Paulo: Perspectiva, 1998.

BOURDIEU, P. Realidade da representação e representação da realidade. Trad. Daniela Kern e Guilherme J. E. Teixeira. 2. ed. rev. In: BOURDIEU, P. A Distinção: crítica social do julgamento. Porto Alegre, Zouk. 2011, p. 446-447.

BOURDIEU, P. Efecto de creencia y estructuras cognitivas. In: CHAMPAGNE, P. et al. (Ed.). Sobre el Estado: Cursos en el Collège de France (1989-1992). Barcelona, Editorial Anagrama, 2015, p. 232-236.

BRASI. Lei n. 9.394, de 20 de dezembro de 1996. Estabelece as Diretrizes e Bases da Educação Nacional. D.O.U. Brasília, Casa Civil da Presidência da República, 1996.

BRASIL. Conselho Nacional de Educação/Conselho Pleno. Resolução CNE/CP 1, de 18 de fevereiro de 2002. Institui Diretrizes Curriculares Nacionais para a Formação de Professores da Educação Básica, em nível superior, curso de licenciatura, de graduação plena. D.O.U., Brasília, 04 de março de 2002, Seção 1, p. 8.

BRASIL. Conselho Nacional de Educação/Conselho Pleno. Resolução CNE/CP n. 1, de 17 de junho de 2004. Institui Diretrizes Curriculares Nacionais para a Educação das Relações Étnico-Raciais e para o Ensino de História e Cultura Afro-Brasileira e Africana. D.O.U., Brasília, 22 de junho de 2004, Seção 1, p. 11.

BRASIL. Conselho Nacional de Educação/Conselho Pleno. Resolução CEN/CP n, 1, de 15 de maio de 2006. Institui Diretrizes Curriculares Nacionais para o Curso de Graduação em Pedagogia, licenciatura. D.O.U., Brasília, 16 de maio de 2006, Seção 1, p. 11.

BRASIL. Lei n. 13.005, 25 de junho de 2014. Aprova o Plano Nacional de Educação PNE e dá outras providências. D.O.U. Brasília, 26 de junho de 2014.

BRASIL. Conselho Nacional de Educação/Conselho Pleno. Resolução CNE/CP 2, de $1^{\circ}$ de julho de 2015. Define as Diretrizes Curriculares Nacionais para a formação inicial em nível superior (cursos de licenciatura, cursos de formação pedagógica para graduados e cursos de segunda licenciatura) e para a formação continuada. D.O.U., de 2 de julho de 2015, Seção 1, p. 8-12.

BRZEZINSKI, I. (Org.). Políticas de Formação do Magistério: ANFOPE em movimento. Goiás, Editora Espaço Acadêmico, 2018. 
FORMAÇÃO DE PROFESSORES NO BRASIL E NA AMÉRICA LATINA

na perspectiva da educação inclusiva

CANEN, A. A pesquisa multicultural como eixo na formação docente: potenciais para a discussão da diversidade e das diferenças. Ensaio: avaliação e políticas públicas em Educação, Rio de Janeiro, Fundação Cesgranrio, v. 16, n. 59, p. 297-308, abr./jun., 2008.

DARLING-HAMMOND, L. Educar con calidad y equidad: los dilemas del siglo XXI, Centro de Innovación en Educación de Fundación Chile, Santiago, 2012.

FREITAS, H. C. L. de. Formação de Professores no Brasil: 10 anos de embate entre projetos de formação. Educação \& Sociedade, Campinas, v. 23, n. 80, set/2002.

GATTI, B. A.; BARRETO, E. S. S.; ANDRÉ, M. E. D. A. A.; ALMEIDA, P. C. A. Professores do Brasil: novos cenários de formação. Brasília, UNESCO, 2019.

MOSCOVICI, S. Psicologia das minorias ativas. Petrópolis: Vozes, 2011.

MOSCOVICI, S. A psicanálise, sua imagem e seu público. Trad. Sonia Fuhrmann. Petrópolis, Vozes, 2012.

UNESCO. Guidelines for Inclusion: Ensuring Acess to Education for All. Paris, UNESCO, 2005.

UNESCO. Directrices sobre políticas de inclusion en la educaión. Paris, UNESCO, 2009. Disponível em: http://unesdoc.unesco.org/images/0017/001778/177849s.pdf.

UNESCO. Education for Sustainable Development Gools: learning objectives. Paris, UNESCO, 2017. Disponível em: http://unesco.org/open-access/terms-use-ccbysa-en.

UNESCO. Estrategia Regional sobre Docentes OREAL-UNESCO Santiago. Formación Inicial Docente en Competencias para el Siglo XXI y Pedagogías para la Inclusión en América Latina: análisis comparativo de siete casos nacionales. Santiago do Chile, OREALC/UNESCO, abril 2018.

Recebido em: 21 mar. 2020. Aprovado em: 20 mai. 2020. 
*Maria de Fátima Barbosa Abdalla é doutora em Educação pela Faculdade de Educação da Universidade de São Paulo/FEUSP. Pós-doutora em Psicologia da Educação pela PUC/SP. Professora do Programa de Pós-Graduação Mestrado e Doutorado em Educação da Universidade Católica de Santos. Líder do Grupo de Pesquisa/CNPq "Instituições de Ensino: políticas e práticas pedagógicas". Membro da ANFOPE e pesquisadora associada ao Centro Internacional de Estudos sobre Representações Sociais e Subjetividade em Educação/CIERS-Ed da Fundação Carlos Chagas/FCC - Cátedra UNESCO de Profissionalização Docente.

E-mail: mfabdalla@uol.com.br

http://orcid.org/0000-0001-8290-959X

**Patrícia Cristina Albieri de Almeida é doutora em Educação pela Universidade Estadual de Campinas. Pesquisadora da Fundação Carlos Chagas/FCC e Professora do Programa de Mestrado Profissional em Educação do UNASP. Líder do Grupo de Pesquisa/CNPq "GEPROF - Grupo de estudos e pesquisas sobre profissão e formação docente".

E-mail: palmeida@fcc.org.br

http://orcid.org/0000-0002-4081-4573 